\title{
Age and body surface area related normal upper and lower limits of $M$ mode echocardiographic measurements and left ventricular volume and mass from infancy to early adulthood
}

\author{
F U Huwez, A B Houston, J Watson, S McLaughlin, P W Macfarlane
}

\begin{abstract}
Background-M Mode echocardiograms can be measured by two different conventions. In addition, normal limits of echocardiographic measurements have customarily been stratified according to age or body surface area. There is therefore a need to develop a more easily managed approach to calculating normal limits of measurements for the two conventions, one of which, the Penn convention, has not previously been used for echocardiographic measurements in
\end{abstract} children.

Methods-M mode echocardiograms were recorded in 127 healthy subjects aged from 7 months to 19.5 years. Measurements were made from paper recordings according to the recommendations of the American Society of Echocardiographers and those of the Penn convention.

Results-Age and body surface area were found to be highly correlated; but for completeness separate age dependent and body surface area dependent equations for the normal limits of $M$ mode echocardiographic variables were developed.

Conclusion-A set of age dependent equations and a set of body surface area dependent equations are presented for easy calculation of upper and lower limits of normal $M$ mode echocardiographic variables in infants and children.

(Br Heart f 1994;72:276-280)

The normal limits of $M$ mode echocardiographic measurements in infants and children were established in the $1970 \mathrm{~s}^{1-3}$ These studies showed that the growth related changes of the echocardiographic measurements are functions of either body surface $\operatorname{area}^{12}$ or body weight. ${ }^{3}$ Henry et al found that $M$ mode echo measurements in infants and children up to early adulthood followed a linear regression either directly on the body surface area or on its square or cube root. ${ }^{4}$ Growth related changes in echocardiographic measurements from infancy to late childhood as a function of age have not been published, however. Furthermore, echocardiographic measurements in infants and children were obtained using a convention which was adopted by the American Society of Echocardiographers. ${ }^{5}$ Later, the Penn convention ${ }^{6}$ was introduced for the measurement of left ventricular dimensions, but this convention has, as yet, not been used to establish the normal limits of left ventricular dimensions in infants and children. These studies were performed with stand alone $\mathbf{M}$ mode transducers, whereas now an $M$ mode record is obtained after using the two dimensional image to provide the optimum position and angulation. Therefore, it was decided to carry out a prospective $M$ mode echocardiographic study in a group of normal infants, children, and young adults $(a)$ to compare the dimensions on American Society of Echocardiographers and Penn conventions and $(b)$ to use age and, separately, body surface area for the development of regression equations to define the upper and lower normal limits of the $M$ mode echocardiographic measurements.

\section{Subjects and methods}

Healthy infants and children were recruited to the study after obtaining parental consent. A few young adults also volunteered. All the subjects were screened by a consultant paediatric cardiologist and none had any echocardiographic Doppler abnormality. The age (in months), weight $(\mathrm{Wt})$ in kilograms $(\mathrm{Kg})$, and the height $(\mathrm{Ht})$ in centimetres $(\mathrm{cm})$ were obtained. The body surface area (BSA) in square metres $\left(\mathrm{m}^{2}\right)$ was calculated according to the following equation. ${ }^{7}$

$$
\text { BSA }\left(m^{2}\right)=(0.0001)(71.84)\left(W t^{0.425}\right)\left(\mathrm{Ht}^{0.725}\right)
$$

Echocardiographic examinations ( $M$ mode and two dimensional) and Doppler studies were obtained for all subjects in the supine position without sedation by using a Vingmed 700 CFM echocardiograph. The two dimensional image was used to obtain the optimum position and angulation of the $M$ mode line. The $M$ mode echocardiogram of the left ventricular dimension was recorded at the level of the mitral valve. Measurements of the end diastolic interventricular septum (IVS), the posterior wall of the left ventricle at end diastole (PWLV), and the left ventricular internal dimension (LVID) at end systole $\left(\mathrm{LVID}_{\mathrm{s}}\right)$ 
and end diastole (LVIDd), were made on American Society of Echocardiographers' and Penn conventions. The American Society of Echocardiographers' recommendations are that measurements should be made from the leading edge of one wall to the leading edge of another at the onset of the QRS complex. On the other hand, according to the Penn convention, measurements should be made at the peak of the $R$ wave with the endocardial echoes of the interventricular septum and posterior wall of the left ventricle being excluded for the septal and wall measurements, but included in the measurement of the left ventricular internal dimension.

The American Society of Echocardiographers' recommendations were used for the measurements of the end diastolic aortic root, maximum aortic valve separation at end systole, left atrium at end systole, and the right ventricular cavity at end diastole. The aortic root dimension was measured from the outside of the anterior aortic root to the outside of the posterior aortic root at the onset of the QRS complex. The aortic valve separation was measured at the inner aspect of the anterior aortic valve to the inner aspect of the posterior valve at the point of maximum excursion at end systole. The left atrial dimension was measured after performing a sweep and demonstrating which of the lines in the left atrium was in continuity with the left ventricular posterior wall. At end ventricular systole the left atrial dimension was measured, including the thickness of the posterior aortic root (which was excluded from the measurement of the aortic root dimension), to the dominant line of the posterior wall of the left atrium as identifiable in the switch gain circuit or by manual clamping. The right ventricular cavity was measured from the right ventricular endocardial surface to the right septal surface at the onset of the QRS complex. The mean of three echo beats was taken as the $M$ mode echocardiographic dimension of each subject in the study.

The left ventricular volumes (LVV) at end systole and end diastole were calculated on the two conventions according to the formula $^{8}$

$$
\mathrm{LVV}=3 \cdot 14(\mathrm{LVID})^{3 / 3}(\mathrm{ml})^{3}
$$

The left ventricular masses (LVM) were calculated from the echocardiographic left ventricular dimension measurements made on both the American Society of Echocardiographers' convention ${ }^{9}$ and on the Penn convention ${ }^{6}$ as follows

LVM $($ ASE $)=1.05\left(\left(\right.\right.$ IVS + PWLV + LVIDd $\left.^{3}-(\text { LVIDd })^{3}\right) g$ LVM $($ Penn $)=1.04\left((\text { IVS + PWLV + LVIDd })^{3}\right.$

$$
\left.(\text { LVIDd) })^{3}\right)-13.6 \mathrm{~g}
$$

The equation for the calculation of the left ventricular mass on the Penn convention was introduced by Devereux and Reichek ${ }^{6}$ for an adult population and its application in very early life would have produced small left ventricular masses. Therefore, the equation was modified so that the constant factor of $13.6 \mathrm{~g}$ was not subtracted from the estimated left ventricular mass in infants and children.
The left ventricular ejection fraction was also calculated using volumes measured according to the two conventions.

The BMDP Biomedical Data program ${ }^{10}$ was used for (a) calculation of the body surface area from the weight and height, $(b)$ calculation of the left ventricular volumes and masses, (c) correlation of the various echocardiographic measurements with the age and the body surface area separately, and (d) development of the regression equations to define the normal upper and lower limits of the $\mathrm{M}$ mode echo measurements.

\section{Results}

One hundred and twenty seven healthy infants and children completed the study. They included 77 boys and 50 girls with an age range of 7 to 234 months (19.5 years) and a mean (SD) age of $66.55(41.63)$ months. Their body surface area ranged from $0.27 \mathrm{~m}^{2}$ to $1.603 \mathrm{~m}^{2}$ with a mean (SD) of $0.735(0.26) \mathrm{m}^{2}$. Table 1 gives the minimum, maximum, mean (SD), and the 96 centile range of the various echocardiographic measurements. In some instances the $M$ mode record of the right ventricular cavity, aorta, or left atrium was not considered suitable for making an accurate measurement.

The Penn measurements of left ventricular internal dimension at end systole and end diastole, and the calculated left ventricular volumes at end systole and end diastole were significantly higher $(P<0.00001)$ than those obtained from the American Society of Echocardiographers' convention. The measurements of the interventricular septum and posterior wall of the left ventricle, and the

Table 1 Means, standard deviations, and 96 centile ranges for the echocardiographic variables studied. All

\begin{tabular}{|c|c|c|}
\hline Echocardiographic variable & Mean (SD) & Range \\
\hline $\begin{array}{l}\text { Aortic root } \\
\text { Aortic valve } \\
\text { Left atrium } \\
\text { Right ventricular cavity }\end{array}$ & $\begin{array}{l}1.684(0.287) \\
1.237(0.256) \\
2.395(0.373) \\
1.206(0.293)\end{array}$ & $\begin{array}{l}1 \cdot 2-2 \cdot 5 \\
0 \cdot 7-2 \cdot 23 \\
1 \cdot 7-3 \cdot 6 \\
0 \cdot 6-2 \cdot 00\end{array}$ \\
\hline $\begin{array}{l}\text { IVS } \\
\text { ASE } \\
\text { Penn }\end{array}$ & $\begin{array}{l}0.643(0.117) \\
0.531(0.115)\end{array}$ & $\begin{array}{l}0.4-1 \cdot 1 \\
0.3-0.95\end{array}$ \\
\hline $\begin{array}{l}\text { PWLV } \\
\text { ASE } \\
\text { Penn }\end{array}$ & $\begin{array}{l}0.565(0.125) \\
0.478(0.121)\end{array}$ & $\begin{array}{l}0 \cdot 3-1 \cdot 0 \\
0 \cdot 3-1 \cdot 0\end{array}$ \\
\hline $\begin{array}{c}\text { LVIDs } \\
\text { ASE } \\
\text { Penn }\end{array}$ & $\begin{array}{l}2 \cdot 156(0 \cdot 349) \\
2 \cdot 328(0 \cdot 363)\end{array}$ & $\begin{array}{l}1 \cdot 3-3 \cdot 0 \\
1.5-3 \cdot 5\end{array}$ \\
\hline $\begin{array}{l}\text { LVIDd } \\
\text { ASE } \\
\text { Penn }\end{array}$ & $\begin{array}{l}3.412(0.50) \\
3.575(0.517)\end{array}$ & $\begin{array}{l}2 \cdot 3-5 \cdot 2 \\
2 \cdot 43-5 \cdot 4\end{array}$ \\
\hline $\begin{array}{l}\text { LVVs } \\
\text { ASE } \\
\text { Penn }\end{array}$ & $\begin{array}{l}11 \cdot 326(5 \cdot 665) \\
14 \cdot 188(7 \cdot 015)\end{array}$ & $\begin{array}{l}2 \cdot 3-28 \cdot 26 \\
3 \cdot 53-44 \cdot 876\end{array}$ \\
\hline $\begin{array}{l}\text { LVVd } \\
\text { ASE } \\
\text { Penn }\end{array}$ & $\begin{array}{l}44.311(20.939) \\
50.864(23.393)\end{array}$ & $\begin{array}{l}12 \cdot 73-147 \cdot 17 \\
15 \cdot 02-164 \cdot 81\end{array}$ \\
\hline $\begin{array}{l}\text { LVM } \\
\text { ASE } \\
\text { Penn }\end{array}$ & $\begin{array}{l}65 \cdot 124(30 \cdot 365) \\
55.525(27 \cdot 59)\end{array}$ & $\begin{array}{l}18.50-212.51 \\
16 \cdot 25-192.95\end{array}$ \\
\hline
\end{tabular}
units are in centimetres

IVS, Interventricular septum; PWLV, left ventricular posterior wall; LVIDs, left ventricular diameter at end systole; LVIDd, wall; LVIDs, left ventricular diameter at end systole; LVIDd,
left ventricular diameter at end diastole; LVVs, left ventricular left ventricular diameter at end diastole; LVVs, left ventricular
volume at end systole; LVVd, left ventricular volume at end volume at end systole; LVVd, left ventricular volume at end
diastole; LVM, left ventricular mass; ASE, American Society diastole; LVM, left ventricular mass; ASE, American
of Echocardiographers; and Penn, Penn convention. 
Figure 1 Relation between age and lefi calculated using the American Society of Echocardiographers recommendations. There was a good correlation between the two variables $(r=0.85)$. ventricular mass (LVM)

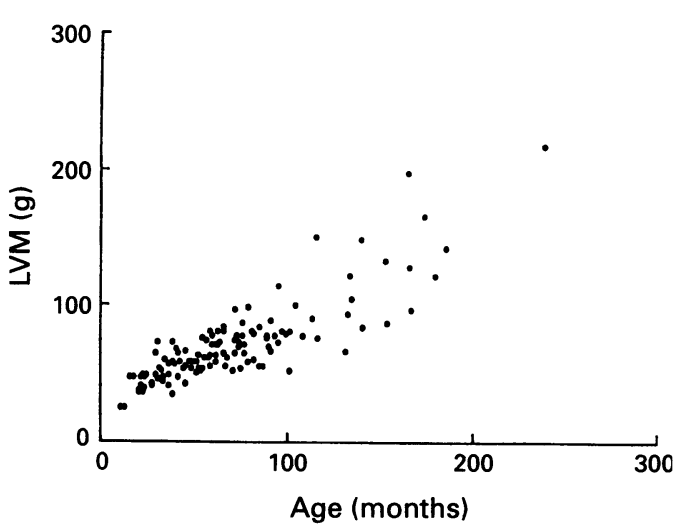

Figure 2 Relation between age and body surface area (BSA) calculated according to the formula of DuBois and formula of DuBois and correlation between the two variables $(r=0.94)$.

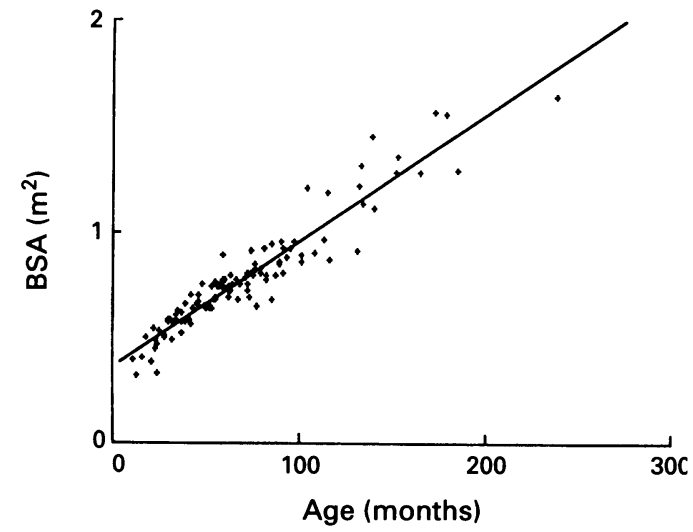

calculated left ventricular mass according to the American Society of Echocardiographers' recommendations were significantly higher $(p$ $<0.00001$ ) than the Penn estimates (table 1). The age (in months) correlated significantly with the echocardiographic measurements with $r$ values ranging from $0.44(P<0.05)$ for the interventricular septum on the Penn convention to an $r$ value of $0.85(P<0.001)$ for the left ventricular mass on the American Society of Echocardiographers' convention (fig 1). Similar significant correlations were found between the body surface area and the echocardiographic measurements with $r$ values ranging from $0.48(P<0.05)$ for the interventricular septum on the Penn convention to an $r$ value of $0.89(P<0.001)$ for the left ventricular mass on the American Society of Echocardiographers' convention. The age (in months) correlated strongly $(r=0.95)$ with the body surface area (fig 2). Therefore it was possible to develop a regression equation that can be used to predict the body surface area (BSA) in $\mathrm{m}^{2}$ from the age in months as follows:

$$
\text { BSA }\left(\mathrm{m}^{2}\right)=0.00594 \times \text { age (months) }+0.503
$$

Nevertheless, it was decided to use the age and, separately, the body surface area as the independent variables to develop the regression equations for the definition of the normal limits of the echocardiographic measurements. Tables 2 and 3 give the continuous equations for each echocardiographic variable.

There was one exception to the significant correlations, namely, that between the ejection fraction and age or body surface area. In view of the poor correlation, continuous equations linking the ejection fraction with dependent variables are not provided.

Because the lower limits of normal values derived from continuous equations in some instances produce negative values for the volume and mass in infants, it is recommended that they are not applied to children under the age of 4 years. The ranges of all variables are available and for children in this young age group the lower limit of normal can be obtained from the range quoted.

\section{Discussion}

To establish a normal range of any anatomical, physiological, or biochemical variable, it is conventional and logical that such ranges are obtained from a sample of the general population who are apparently healthy as was each patient being studied. The same approach has been used in previous studies in neonates, infants, and children. ${ }^{124}$ Children with retarded growth or debilitating disease were excluded from those studies, as they were from the present study. If the present limits, as calculated in this paper, are to be applied to a child with retarded growth, this would have to be taken into account by the consulting doctor. The present paper simply presents normal values derived from a group of healthy children. The alternative of including a group of children with retarded growth in the estimate of normal limits did not seem appropriate in the development of the equations listed in table 2.

Echocardiography has an established role in the diagnosis of congenital and acquired

Table 2 M-Mode echocardiographic measurements in centimetres determined using the American Society of Echocardiographers' convention only. The age dependent continuous equation to predict the upper and lower $97.5 \%$ limits of each echocardiographic variable is given. The upper limit is obtained using the "+" sign and the lower limit is obtained by using the "-" sign where \pm is positioned

\begin{tabular}{lll}
\hline Echocardiographic variable & Age dependent equations & BSA dependent equations \\
\hline Aortic root & $\mathrm{y}=1.335+0.0052 \times$ age (months) \pm 0.3673 & $\mathrm{y}=1.05+0.8522 \times \mathrm{BSA}\left(\mathrm{m}^{2}\right) \pm 0.371$ \\
Aortic valve & $\mathrm{y}=0.8936+0.005 \times$ age(months) \pm 0.2994 & $\mathrm{y}=0.62119+0.8248 \times \mathrm{BSA}\left(\mathrm{m}^{2}\right) \pm 0.31517$ \\
Left atrium & $\mathrm{y}=2.0698+0.0049 \times$ age(months) \pm 0.6171 & $\mathrm{y}=1.7666+0.8281 \times \mathrm{BSA}\left(\mathrm{m}^{2}\right) \pm 0.56901$ \\
Right ventricular cavity & $\mathrm{y}=1.0693+0.002 \times$ age (months) \pm 0.5547 & $\mathrm{y}=0.97597+0.31595 \times \mathrm{BSA}\left(\mathrm{m}^{2}\right) \pm 0.55587$ \\
\hline BSA = Body surface area. & &
\end{tabular}


Table 3 M-Mode echocardiographic measurements in centimetres on American Society of Echocardiographers' (ASE) and Penn conventions with the corresponding continuous equations to predict the upper and lower normal limits. The upper limit is obtained using the " + " sign and the lower limit is obtained by using "-" sign where \pm is positioned

\begin{tabular}{|c|c|c|}
\hline Echocardiographic variable & Age dependent equations & BSA dependent equations \\
\hline $\begin{array}{c}\text { IVS } \\
\text { ASE } \\
\text { Penn }\end{array}$ & $\begin{array}{l}y=0.549+0.0014 \times \text { age (months) } \pm 0.1999 \\
y=0.4505+0.0012 \times \text { age (months) } \pm 0.2044\end{array}$ & $\begin{array}{l}y=0.44403+0.26817 \times \text { BSA }\left(m^{2}\right) \pm 0.18885 \\
y=0.36946+0.21711 \times \text { BSA }\left(m^{2}\right) \pm 0.20117\end{array}$ \\
\hline $\begin{array}{r}\text { PWLV } \\
\text { ASE } \\
\text { Penn }\end{array}$ & $\begin{array}{l}y=0.441+0.0019 \times \text { age (months) } \pm 0.1944 \\
y=0.3613+0.0017 \times \text { age }(\text { months }) \pm 0.1916\end{array}$ & $\begin{array}{l}y=0.32994+0.31271 \times \text { BSA }\left(m^{2}\right) \pm 0.18396 \\
y=0.25636+0.29259 \times \text { BSA }\left(m^{2}\right) \pm 0.175\end{array}$ \\
\hline $\begin{array}{c}\text { LVIDs } \\
\text { ASE } \\
\text { Penn }\end{array}$ & $\begin{array}{l}y=1.7392+0.0063 \times \text { age (months) } \pm 0.4588 \\
y=1.8831+0.0067 \times \text { age (months) } \pm 0.4593\end{array}$ & $\begin{array}{l}y=1.3988+1.0295 \times \text { BSA }\left(m^{2}\right) \pm 0.44889 \\
y=1.5308+1.0831 \times \text { BSA }\left(m^{2}\right) 0.45459\end{array}$ \\
\hline $\begin{array}{c}\text { LVIDd } \\
\text { ASE } \\
\text { Penn }\end{array}$ & $\begin{array}{l}y=2.7442+0.01 \times \text { age (months) } \pm 0.5446 \\
y=2.892+0.01 \times \text { age (months) } \pm 0.5757\end{array}$ & $\begin{array}{l}y=2.2366+1.59 \times \text { BSA }\left(m^{2}\right) \pm 0.52196 \\
y=2.3641+1.6395 \times B S A\left(m^{2}\right) \pm 0.56754\end{array}$ \\
\hline $\begin{array}{c}\text { LVVs` } \\
\text { ASE } \\
\text { Penn }\end{array}$ & $\begin{array}{l}y=4.4212+0.1037 \times \text { age (months) } \pm 7.24 \\
y=5.5027+0.1305 \times \text { age (months) } \pm 8.7639\end{array}$ & $\begin{array}{l}y=-1 \cdot 1627+16.99 \times \text { BSA }\left(m^{2}\right) \pm 7 \cdot 1248 \\
y=-1.2816+21.021 \times \text { BSA }\left(m^{2}\right) \pm 8.6843\end{array}$ \\
\hline $\begin{array}{c}\text { LVVd }^{\star} \\
\text { ASE } \\
\text { Penn }\end{array}$ & $\begin{array}{l}y=16.043+0.4248 \times \text { age (months) } \pm 22.1487 \\
y=19.236+0.4752 \times \text { age (months) } \pm 24.6529\end{array}$ & $\begin{array}{l}y=-4.0429+65.285 \times \text { BSA }\left(\mathrm{m}^{2}\right) \pm 21.6282 \\
y=-3.9672+74.222 \times B S A\left(m^{2}\right) \pm 25.0475\end{array}$ \\
\hline $\begin{array}{c}\text { LVM^ } \\
\text { ASE } \\
\text { Penn }\end{array}$ & $\begin{array}{l}y=23.901+0.61941 \times \text { age (months) } \pm 31.67 \\
y=18.923+0.55 \times \text { age (months) } \pm 30.4136\end{array}$ & $\begin{array}{l}y=-9.9498+101.03 \times \text { BSA }\left(m^{2}\right) \pm 26.26678 \\
y=-10.239+88.263 \times \text { BSA }\left(m^{2}\right) \pm 24.3888\end{array}$ \\
\hline
\end{tabular}

*The lower limits are not meaningful under 4 years of age. IVS, Interventricular septum; PWLV, left ventricular posterior wall; LVIDs, left ventricular diameter at end systole; LVIDd, left ventricular diameter at end diastole; LVVs, left ventricular volume at end systole; LVVd, left ventricular volume at end diastole; LVM, left ventricular mass; ASE, American Society of Echocardiographers; and Penn, Penn convention

heart disease. Furthermore, quantitative echocardiography also has a definite role in the assessment, management, and evaluation of the prognosis of these disorders. For the above mentioned reasons, the normal ranges of echocardiographic dimensions of cardiac chambers and great vessels have been established for neonates ${ }^{11}$ and for infants and children. ${ }^{1,3,4}$ These normal values have been adjusted either to the weight ${ }^{3}$ or to the body surface area. ${ }^{12}$ Epstein et al ${ }^{1}$ suggested that plotting the echocardiographic measurement data against the age is illogical because at each age there is a wide spectrum of body sizes. Therefore they preferred body surface area to standardise the $M$ mode echocardiographic measurements in their population. In our study, the age strongly correlated with the body surface area $(r=0.95)$. In addition, it was thought to be of value to develop a simpler approach to measurement normalisation such that a quick calculation based on age (as in table 2) could produce normal limits for a particular measurement. Therefore, to reconcile the two points of view, a decision was made to provide two sets of equations to predict normal echocardiographic limits, one based on age as the dependent variable and the other based on body surface area. Figure 1 gives an example of the good positive correlation between age and an echocardiographic measurement. It shows the direct linear relation of left ventricular mass with age on the American Society of Echocardiographers' convention. In this study, the normal minimum and maximum limits of each $M$ mode echocardiographic measurement are presented for an age group from 7 to 234 months ( 19.5 years). The whole population was not subdivided into different age groups or to different groups on the basis of body weight. Instead, a method was developed to predict the normal limits of these echocardio- graphic measurements from continuous equations dependent on age or body surface area. The use of the former saves the echocardiographer $(a)$ calculating the body surface area from the nomograms after obtaining the weight and height and (b) referring to tables of echocardiographic measurements standardised on the basis of the body weight as at least five different ranges of normal values have been suggested for each echocardiographic parameter based on the body weight. Discontinuities in limits are also avoided. As an example consider the equation for left ventricular mass according to American Society of Echocardiographers (table 3)

Limits $=23.901+0.61941 \times$ age (months) \pm 31.67

At age 5 years the equation reduces to

$$
\text { Limits }=23 \cdot 9+37 \cdot 2 \pm 31 \cdot 67=61 \cdot 1 \pm 31 \cdot 67
$$

The upper limit of left ventricular mass is therefore $92.77 \mathrm{~g}$ and the lower limit is $29.44 \mathrm{~g}$ for age 5 years.

Equations have been provided where the dependent variable is age and where it is body surface area. For children with normal growth, either equation is suitable. It can certainly be argued that for children with retarded growth, it is more meaningful to use the equation based on body surface area, but it has to be borne in mind that this equation has been developed from healthy subjects. Nevertheless, the values provided should still be meaningful in a child with growth retardation.

Furthermore, in this study the Penn convention has been used for the first time in children for the measurement of the left ventricular dimensions. The measurements of left ventricular internal dimension at end systole and end diastole on the Penn convention were significantly higher $(P<0.00001)$ than the American Society of Echocardiographers' estimates and this inevitably resulted in sig- 
nificantly higher $(P<0.00001)$ left ventricular volumes on the Penn convention compared with the American Society of Echocardiographers' estimates. The interventricular septum and the posterior wall of the left ventricle were significantly higher $(P<0.00001)$ on American Society of Echocardiographers' recommendations than on the Penn convention and this resulted in higher left ventricular mass $(P<0.00001)$ calculated according to the equation of Troy et $a l$ compared with those obtained from the Penn convention.

Devereux and Reichek ${ }^{6}$ showed that the left ventricular mass calculated from measurements of left ventricular dimensions according to the American Society of Echocardiographers' recommendations significantly overestimated the weight of the left ventricle measured at necropsy and this led them to introduce the Penn convention to calculate the left ventricular mass from $M$ mode echocardiograms. Therefore, the subtle differences of left ventricular dimensions on American Society of Echocardiographers' and Penn conventions produce significant differences in left ventricular volumes and masses which should be taken into account when these echocardiographic parameters are used for the assessment of patients with left ventricular hypertrophy/dilatation.

It should be stressed that the results presented here are not a recommendation for using either the Penn convention or the recommendations of the American Society of Echocardiographers. They are provided for completeness as the two techniques were used in the study. It is for the individual user to decide which is most appropriate.
Finally, it can be concluded from this study that $(a)$ echocardiographic left ventricular dimensions in infants and children differ significantly on American Society of Echocardiographers' and Penn conventions and $(b)$ the echocardiographic measurements in normal infants and children up to early adulthood are age or body surface area dependent, thereby allowing the development of continuous equations to define the upper and lower normal limits.

1 Epstein ML, Goldberg ST, Allen HD, Konecke L, Wood J. Great vessel, cardiac chamber and wall growth patterns in normal children. Circulation 1975;51:1124-9.

2 Allen HD, Goldberg ST, Sahn DJ, Schy N, Wojcik R. A quantitative echocardiographic study of champion childquantitative echocardiographic study of champ

3 Lundstrom NR. Clinical applications of echocardiography in infants and children. I. Investigation of infants and in infants and children. I. Investigation of infants and 1974;63:23-32.

4 Henry WL, Ware J, Gardin JM, Hepner SI, McKay J, Weiner $\mathbf{M}$. Echocardiographic measurements in normal subjects: growth related changes that occur between infancy and early adulthood. Circulation 1978;57:278-85.

5 Sahn DJ, DeMaria A, Kisslo J, Weyman A. Recommendations regarding quantitation in $\mathrm{M}$-mode echocardiography. Results of survey of echocardiographic measurements. Circulation 1978;58:1072-82.

6 Devereux RB, Reichek N. Echocardiographic determination of left ventricular mass in man. Circulation 1977;55:613-8.

7 DuBois D, DuBois EF. A formula to estimate approximate surface area if height and weight be known. Arch Intern Med 1916;1 17:863-71.

8 Pombo JF, Troy BL, Russell RO Jr. Left ventricular volumes and ejection fraction by echocardiography.

9 Troy BL, Pombo J, Rackley CE. Measurement of left ventricular wall thickness and mass by echocardiography. Circulation 1972;45:602-11.

10 Dixon WT, Brown MB, Engleman L, et al. BMDP statistical software. Berkeley: University of California Press, 1977:339-417.

11 Hagan AD, Deely WJ, Sahn D, Friedman WF. Echocardiographic criteria for normal newborn infants. Circulation 1973;48:1221-6. 